\title{
Mangled Extremity: Amputation Versus Salvage
}

\author{
Mayur B. Patel • Kathleen M. Richter • Shahid Shafi
}

Published online: 11 January 2015

(C) Springer International Publishing AG 2015

\begin{abstract}
The mangled extremity is defined as massive anatomic disruption of the bone, muscle, tendon, nerve, vasculature, and/or soft tissue that threatens limb viability and functionality. The clinical team is left with the decision whether to amputate or salvage and reconstruct. The decision should integrate baseline factors (e.g., pre-injury comorbidities, functional status), injury factors (e.g., location and severity of mangled extremity, wound contamination, total burden of traumatic injuries, physiologic severity of illness), patient preference, and available personnel and resources. From the primary survey through the recovery phases, the management is best summarized as "life before limb". Extremity tourniquets are key adjuncts in managing uncontrolled hemorrhage. Amputation or limb salvage, both are associated with risks of long-term disability and unemployment. Management decisions should be patient-centered and multidisciplinary with extensive communication among providers, patients, and families, and should be appropriately documented.
\end{abstract}

This article is part of the Topical Collection on Trauma to the Lower Extremities

\section{B. Patel}

Veterans Affairs (VA) Tennessee Valley Healthcare System,

Nashville VA Medical Center, Nashville, TN, USA

e-mail: mayur.b.patel@vanderbilt.edu

\section{B. Patel}

Division of Trauma \& Surgical Critical Care, Department Of Surgery and Neurosurgery, Section of Surgical Sciences, Vanderbilt University School of Medicine, 121121 st Avenue South, 404 Medical Arts Building, Nashville, TN 37212, USA

K. M. Richter $\cdot$ S. Shafi $(\bowtie)$

Baylor Scott \& White Health, 8080 N Central Expressway, Suite 900, Dallas, TX 75206, USA

e-mail: shahid.shafi@baylorhealth.edu

K. M. Richter

e-mail: kathleri@baylorhealth.edu
Keywords Mangled extremity $\cdot$ Leg-threatening · Amputation $\cdot$ Limb salvage $\cdot$ Disability $\cdot$ Unemployment . Tourniquet $\cdot$ Fasciotomy $\cdot$ Shunt

\section{Introduction}

A mangled extremity is broadly defined as massive anatomic disruption of the bone, muscle, tendon, nerve, vasculature, and/or soft tissue that threatens limb viability and functionality. The most important clinical decision at the time is whether to amputate the mangled extremity or attempt to salvage it. This decision should be based upon pre-injury health status (such as comorbidities and functional status), injury factors (e.g., location and severity of mangled extremity, wound contamination, associated injuries, physiologic severity of illness), patient preference, and available personnel and resources (Table 1).

\section{Civilian Outcomes: Scoring Systems for Mangled Extremity Outcomes}

Multiple scoring systems have been developed to evaluate the severity of mangled lower extremity. These include the Hannover fracture scale (HFS) [1]; mangled extremity severity index (MESI) [2]; predictive salvage index (PSI) [3]; mangled extremity severity score (MESS) [4]; limb salvage index (LSI) [5]; and nerve injury, ischemia, soft-tissue injury, skeletal injury, shock, and age of patient score (NISSA) [6]. However, none of these systems have been shown to be useful in prospective clinical decision making for amputation versus salvage [7-9]. 
Table 1 Key principles in the management of the mangled extremity

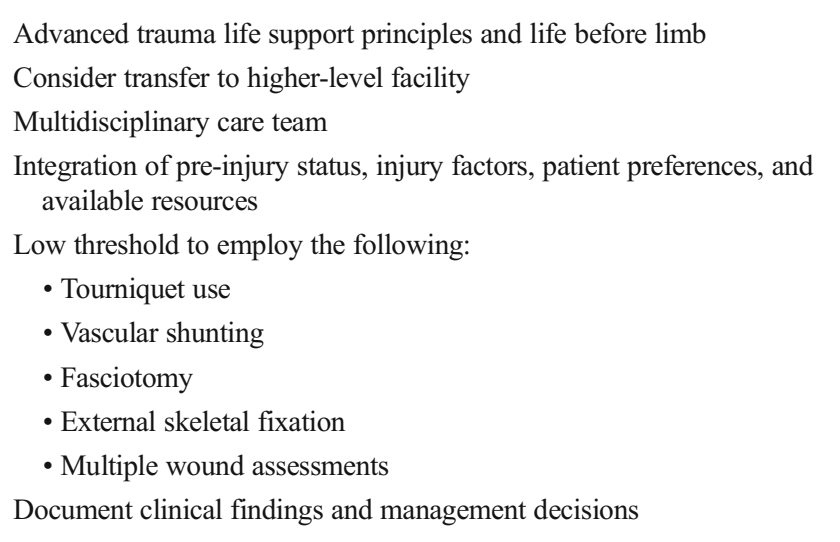

\section{Civilian Outcomes: Lower-Extremity Assessment Project}

The LEAP study still represents the highest level of evidence for the management of the mangled extremity. It was a multicenter prospective cohort of 601 patients enrolled at eight level I trauma centers between 1994 and 1997 who sustained high-energy lower-extremity injuries resulting in mangled extremities. The primary outcome was the Sickness Impact Profile (SIP) measured for several months after the injury. SIP is a self-reported measure of health status with scores that ranged from 0 to 100 , with a score of $>10$ indicating severe disability [10]. Contrary to the hypothesis that an early amputation would have better outcomes than limb salvage with reconstruction at the 2-year follow-up of the remaining 460 subjects, there was no difference in health status between patients who underwent amputation $(n=130)$ and those who underwent limb salvage $(n=330)$. However, limb salvage patients were more likely to require repeat hospitalizations (48 versus $34 \%, p=0.002$ ). In addition, 174 patients with specific hindfoot or ankle injuries, who required free flaps and/or ankle arthrodesis, had worse overall outcomes (SIP score 2.5 points higher, $p=0.014$ ) as well as worse psychosocial outcomes (8.4 points higher, $p=0.013$ ) [11]. In the complete LEAP cohort, more than $40 \%$ of the patients manifested severe disability, and only $50 \%$ returned to work. Predictors of poor outcomes included rehospitalization for a major complication, non-white race, lower socioeconomic status (e.g., low educational level, poverty, lack of private health insurance, poor social support network), low self-efficacy, smoking, and involvement in disability-compensation litigation [12]. These findings suggest potential practical strategies, such as promoting self-efficacy, smoking cessation, and improved access to post-acute care that may improve functional outcomes after sustaining a mangled extremity.

More recently, a retrospective study of 1354 adults with mangled lower extremities treated at 222 level I and II trauma centers was undertaken using the 2007-2009 National
Trauma Databank. Only $21 \%(n=278)$ of the patients underwent amputation, with nearly half of those $(n=124)$ occurring early (defined as before the end of the first calendar day following emergency department arrival). Amputation was more likely with certain types of limb injuries, a highenergy mechanism, associated injuries (severe head injury, and hypotension with systolic blood pressure less than $90 \mathrm{mmHg}$ ), but not with baseline patient factors (age, comorbidities, or insurance status) [13•].

\section{Military Outcomes of the Mangled Extremity}

In a retrospective cohort study [14 ${ }^{\circ}$ utilizing the Expeditionary Medical Encounter Database from the Afghanistan and Iraq wars from 2001 to 2008, there were 587 early amputees (within 90 days of injury), 84 late amputees (greater than 90 days of injury), and 117 limb salvage patients. Their health outcomes were followed for 24 months post-injury adjusted for age, mechanism of injury, injury epoch (2001-2005 versus 2006-2008), injury level (above or below knee), and pre-injury psychological diagnosis. Compared to limb salvage patients, early amputees had similar physical outcomes but a lower rate of psychological disorders such as post-traumatic stress disorder (PTSD) and substance abuse, and received more outpatient treatment. Late amputees demonstrated the worst psychological and physical outcomes, with increased rates of physical and mental health diagnoses as well as protracted pain issues and infections when compared with early amputees and limb salvage subjects.

Preventable exsanguinating hemorrhage from extremity injuries was a major concern in the Vietnam and Somali conflicts, and tourniquet use was the last line of first aid. Now, the frequency of tourniquet use has markedly increased in the management of the mangled extremity. This is, in large part, due to extensive recent military experiences in Afghanistan and Iraq, demonstrating improved hemorrhage control without adverse events $[15,16]$. A prospective study at a Combat Support Hospital in Iraq, over 7 months in 2006, studied 428 tourniquet applications on 309 injured extremities. The findings suggested a survival benefit with the use of prehospital tourniquets (mortality 22 of 194, $11 \%$ ) compared to later application in the emergency department (mortality 9 of $38,24 \%$ ). Also, there was an association between tourniquet use (applied before development of shock) and survival [17]. An important issue with tourniquet is ensuring correct technique to ensure complete arterial occlusion, not just venous outflow obstruction $[18,19]$.

\section{Management of the Mangled Extremity: Primary Survey}

At initial evaluation, primary survey and immediate lifesustaining interventions take precedence over the care of the 
mangled extremity. This principle of management is best summarized as "life before limb" [20•, 21••]. This is emphasized in all civilian and military trauma training courses (e.g., Prehospital Trauma Life Support, Advanced Trauma Life Support, Rural Team Trauma Development, Battlefield Advanced Trauma Life Support). Therefore, the only critical aspect of the mangled extremity management during primary survey is hemorrhage control $[20 \bullet, 21 \bullet, 22]$.

Direct pressure followed by a compressible hemostatic dressing is the simplest initial maneuver, with a low threshold for early application of a proximal extremity tourniquet. Operative management may be required for controlling surgical bleeding. Any hemorrhage control method requires constant reassessment throughout resuscitation, with a clear documentation of the extremity ischemia time. This information could impact clinical decisions such as tourniquet release, need for fasciotomy, or decision to proceed with amputation. Along with hemorrhage control, these patients also need adequate resuscitation that includes blood component (platelet, plasma, and packed red blood cell), depending upon the degree of blood loss $[20 \bullet, 21 \bullet \bullet]$.

\section{Management of the Mangled Extremity: Secondary Survey}

A detailed assessment of the mangled extremity should be carried out during the secondary survey. This should include an assessment and documentation of injuries to the bones, soft tissues (skin, muscles, tendons), and neurovascular status proximal and distal to the injury as well as comparison to the uninjured contralateral limb.

Temporary skeletal stabilization using splints is applied to control hemorrhage, improve bone alignment, reduce pain, and in some cases, decrease ischemia by improving vascular run-off. External fixators can be applied at the bedside. Splints and/or fixation should allow access to open wounds and any tourniquets $[20 \bullet, 21 \bullet \bullet, 22]$.

Extent of skin loss should be assessed as it has important implications for subsequent treatment options. Wound contamination should be addressed early. Tetanus prophylaxis should be administered and broad-spectrum antibiotics started promptly. Sterile gauze can be applied to the open wounds, but formal debridement should be performed in the operating room, unless absolutely required for patient extrication [21••].

Early neurovascular examination and its documentation are essential. Vascular assessment adjuncts to the clinical exam include bedside Doppler assessments using the ankle-brachial index (ankle-ankle or brachial-brachial index, as appropriate). Indices less than 0.9 suggest need for further assessment, including angiography in radiology or the operating room. It is extremely challenging to differentiate the extent of peripheral nerve injuries at this stage. This assessment can be further confounded by the presence of shock, concomitant injuries such as traumatic brain injury, or extensive soft tissue loss $[20 \bullet, 21 \bullet \cdot, 22]$.

Definitive care of the mangled extremity requires a multidisciplinary team comprised of emergency medicine, trauma surgery, nursing, anesthesiology, intensive care unit, orthopedic/hand surgery, plastic surgery, burn surgery, and/ or vascular surgery teams. Consultation with appropriate specialists and/or transfer to higher-level facilities should be considered early, particularly if operative capabilities and/or specialists are not available. Participation of the patient and/or family is critical in the decision making. Documentation should reflect clinical and imaging findings, specialist recommendations, and management decisions. High-quality photographs of the mangled extremity can serve as strong communication tools among providers as well as with the patients and their families $[21 \bullet \cdot]$.

\section{Management of the Mangled Extremity: Operative Management}

The first priority during operative management remains hemorrhage control. This is followed by a detailed evaluation of anatomic severity of the mangled extremity by appropriate surgical specialists. Operative options include shunting or repair of major vascular injuries, debridement of non-viable tissue, bone stabilization using internal or external fixators, prophylactic and/or therapeutic fasciotomy, and amputation. In the face of combined major vascular injury and long bone fractures, shunting followed by external fixators are expedient damage control options. Even without systemic anticoagulation, temporary shunts (e.g., Argyle, Javid, Pruiit-Inahara, pediatric feeding tube, intravenous tubing) can rapidly restore distal flow. This allows time for definitive vascular repair with autologous vein or prosthetic grafts under more controlled circumstances at a later stage $[20 \bullet, 23]$. It should be emphasized that whether a temporary shunt is placed or a definitive repair performed, adequacy of distal flow must be objectively documented (e.g., on-table angiogram) and serially monitored by physical examination and/or bedside Doppler.

There should be a low threshold to perform fasciotomy in patients that are either at high risk for development of compartment syndrome (prophylactic) or if they already have evidence of elevated compartment pressures (therapeutic). Prophylactic fasciotomy should be considered in the presence of prolonged ischemia (greater than $4 \mathrm{~h}$ ), myoglobinuria, combined arterial and venous injuries, anticipated prolonged transport to higher-level facilities, and/or significant reperfusion injury after revascularization. One of the most common errors in the double-incision four-compartment fasciotomy for the lower extremities is incomplete fascial release, specifically, missing the anterior compartment. Future closure of the 
fasciotomy sites may require split-thickness skin grafting. Other complications of fasciotomy include venous injury and congestion, peripheral motor or sensory nerve injury, infection, scarring, and long-term contractures $[21 \bullet \bullet, 22]$.

The decision of limb amputation versus salvage should take into account pre-injury factors (e.g., comorbidities, functional status), injury factors (e.g., severity of mangled extremity, wound contamination, total burden of traumatic injuries, physiologic severity of illness), patient preference, and available personnel and resources, ensuring that the ultimate decision prioritizes the patient's life over limb. Multidisciplinary management and discussions are essential and should include the patient and/or family if time permits. These discussions should be timely, transparent, non-coercive, and clearly documented. Limb replantation is generally only possible with clean-cut injuries, short prehospital times, limited contamination, and an experienced multispecialty team. Circumferential loss of soft tissue poses challenges for adequate coverage of any associated bony and vascular injuries, and should be taken into account as well. Contamination may influence the time before final wound or amputation stump closure, and multiple debridements and repeated wound assessments are often appropriate using copious irrigation, but not under pressure as it may drive contamination into deeper uninjured tissues $[21 \bullet \bullet]$.

In general, the level of amputation should be as distal as possible. An appropriate length of the stump is one that enables proper fitting of a prosthesis that will achieve the best functional outcomes. Given the presence of multiple joints in the upper extremity, limb-length preservation is a more important consideration for upper-extremity injuries even if ultimately dysfunctional. For the forearm amputations, it is ideal to preserve at least $50 \%$ of the radius to maximize function $[21 \bullet \cdot]$. Early post-operative consultation with rehabilitation specialists is also beneficial, especially if immediate amputation is not required to save life.

\section{Complications of Limb Salvage or Amputation in Mangled Extremity}

Skin and soft tissue breakdown, ulceration, rashes, abscesses, deep soft tissue infection, chronic venous congestion, and/or osteomyelitis may affect amputations or limb salvage patient. Chronic pain may affect either method of management. These complications may require secondary or late amputation, or amputation revision. Heterotopic ossification, aberrant lamellar bone formation in non-osseous soft tissue, may develop from high-energy or blast-related injuries, as well as multisystem trauma with traumatic brain injury. Radiation or nonsteroidal anti-inflammatory agents have been used to prevent this complication in high-risk groups [24-26]. Extensive psychosocial support, rehabilitation, orthotics, and prosthetics may help optimize long-term outcomes [20•, 21••, 22].

\section{Conclusion}

The massive anatomic disruption that defines a mangled extremity leaves the clinical team with the decision whether to amputate or salvage and reconstruct. The decision should integrate baseline pre-injury factors, injury factors, patient preference, and available personnel and resources. There is no grading or scoring system that can predict the need for amputation or functional recovery after limb salvage with reconstruction. From the primary survey through the recovery phases, the management is best summarized as "life before limb". Extremity tourniquets are key adjuncts in managing uncontrolled hemorrhage. Amputation or limb salvage, are both associated with risks of long-term disability and unemployment. Management decisions should be patient-centered and multidisciplinary with extensive communication among providers, patients, and families, and should be appropriately documented, including photographs of the mangled extremity.

\section{Compliance with Ethics Guidelines}

Conflict of Interest Mayur B. Patel, Kathleen M. Richter, and Shahid Shafi declare a Vanderbilt Physician-Scientist Development grant.

Human and Animal Rights and Informed Consent This article does not contain any studies with human or animal subjects performed by any of the authors.

Sources of Support Vanderbilt Physician-Scientist Development grant (m.b.p.)

\section{References}

Papers of particular interest, published recently, have been highlighted as:

- Of importance

•. Of major importance

1. Tscherne H, Oestern HJ. A new classification of soft-tissue damage in open and closed fractures (author's transl). Unfallheilkunde. 1982;85:111-5.

2. Gregory RT, Gould RJ, Peclet M, Wagner JS, Gilbert DA, Wheeler JR, et al. The mangled extremity syndrome (M.E.S.): a severity grading system for multisystem injury of the extremity. J Trauma. 1985;25:1147-50.

3. Howe HR, Poole GV, Hansen KJ, Clark T, Plonk GW, Koman LA, et al. Salvage of lower extremities following combined orthopedic and vascular trauma. A predictive salvage index. Am Surg. 1987;53:205-8.

4. Johansen K, Daines M, Howey T, Helfet D, Hansen ST. Objective criteria accurately predict amputation following lower extremity trauma. J Trauma. 1990;30:568-72. discussion 572-3.

5. Russell WL, Sailors DM, Whittle TB, Fisher DF, Burns RP. Limb salvage versus traumatic amputation. A decision based on a sevenpart predictive index. Ann Surg. 1991;213:473-80. discussion 480-1. 
6. McNamara MG, Heckman JD, Corley FG. Severe open fractures of the lower extremity: a retrospective evaluation of the mangled extremity severity score (MESS). J Orthop Trauma. 1994;8:81-7.

7. Stewart DA, Coombs CJ, Graham HK. Application of lower extremity injury severity scores in children. J Child Orthop. 2012;6: 427-31.

8. Stewart D, Coombs C, Graham H. Evaluation of mangled extremity severity score (MESS) as a predictor of lower limb amputation in children with trauma. Eur J Pediatr Surg. 2013;23:333-4.

9. Bosse MJ, MacKenzie EJ, Kellam JF, Burgess AR, Webb LX, Swiontkowski MF, et al. A prospective evaluation of the clinical utility of the lower-extremity injury-severity scores. J Bone Joint Surg Am. 2001;83-A:3-14.

10. Bosse MJ, MacKenzie EJ, Kellam JF, Burgess AR, Webb LX, Swiontkowski MF, et al. An analysis of outcomes of reconstruction or amputation after leg-threatening injuries. N Engl J Med. 2002;347:1924-31.

11. Ellington JK, Bosse MJ, Castillo RC, MacKenzie EJ, LEAP Study Group. The mangled foot and ankle: results from a 2-year prospective study. J Orthop Trauma. 2013;27:43-8.

12. MacKenzie EJ, Bosse MJ, Pollak AN, Webb LX, Swiontkowski MF, Kellam JF, et al. Long-term persistence of disability following severe lower-limb trauma. Results of a seven-year follow-up. J Bone Joint Surg Am. 2005;87:1801-9.

13. de Mestral C, Sharma S, Haas B, Gomez D, Nathens AB. A contemporary analysis of the management of the mangled lower extremity. J Trauma Acute Care Surg. 2013;74: 597-603. Given the LEAP cohort was accrued over 15 years ago with external validity limited to Level I trauma centers, this is a retrospective cohort of 1,354 adults with mangled lower extremities treated at 222 Level I and II trauma centers constructed using the 2007-2009 National Trauma Databank.

14. Melcer T, Sechriest VF, Walker J, Galarneau M. A comparison of health outcomes for combat amputee and limb salvage patients injured in Iraq and Afghanistan wars. J Trauma Acute Care Surg. 2013;75:S247-54. This retrospective cohort study outlines health outcomes of patients undergoing lower extremity limb salvage or amputation from the Afghanistan and Iraq wars from 2001 to 2008 captured primarily in the Expeditionary Medical Encounter Database.
15. Beekley AC, Sebesta JA, Blackbourne LH, Herbert GS, Kauvar DS, Baer DG, et al. Prehospital tourniquet use in Operation Iraqi Freedom: effect on hemorrhage control and outcomes. J Trauma. 2008;64:S28-37. discussion S37.

16. Kragh JF, Walters TJ, Baer DG, Fox CJ, Wade CE, Salinas J, et al. Practical use of emergency tourniquets to stop bleeding in major limb trauma. J Trauma. 2008;64:S38-49. discussion S49-50.

17. Kragh JF, Walters TJ, Baer DG, Fox CJ, Wade CE, Salinas J, et al. Survival with emergency tourniquet use to stop bleeding in major limb trauma. Ann Surg. 2009;249:1-7.

18. King DR, van der Wilden G, Kragh Jr JF. Forward assessment of 79 prehospital battlefield tourniquets used in the current war. J Spec Oper Med. 2011;12:33-8.

19. Kragh JF, Burrows S, Wasner C, Ritter BA, Mazuchowski EL, Brunstetter T, et al. Analysis of recovered tourniquets from casualties of operation enduring freedom and operation new dawn. Mil Med. 2013;178:806-10.

20. Scalea TM, DuBose J, Moore EE, West M, Moore FA, McIntyre R, et al. Western trauma association critical decisions in trauma: management of the mangled extremity. J Trauma Acute Care Surg. 2012;72:86-93. This is a society based guideline for the management of the mangled extremity with an associated algorithm.

21.• Rush RM, Arrington ED, Hsu JR. Management of complex extremity injuries: tourniquets, compartment syndrome detection, fasciotomy, and amputation care. Surg Clin North Am. 2012;92: 987-1007-ix. This is an outstanding comprehensive review of the management of complex extremity injuries.

22. Rush RM, Beekley AC, Puttler EG, Kjorstad RJ. The mangled extremity. Curr Probl Surg. 2009;46:851-926.

23. Taller J, Kamdar JP, Greene JA, Morgan RA, Blankenship CL, Dabrowski $\mathrm{P}$, et al. Temporary vascular shunts as initial treatment of proximal extremity vascular injuries during combat operations: the new standard of care at Echelon II facilities? J Trauma. 2008;65: 595-603.

24. Edwards DS, Clasper JC. Heterotopic ossification: a systematic review. J R Army Med Corps. 2014. doi:10.1136/jramc-2014-000277.

25. Kan L, Kessler JA. Evaluation of the cellular origins of heterotopic ossification. Orthopedics. 2014;37:329-40.

26. Matsumoto ME, Khan M, Jayabalan P, Ziebarth J, Munin MC. Heterotopic ossification in civilians with lower limb amputations. Arch Phys Med Rehabil. 2014;95:1710-3. 